\title{
Custos e precificação: um estudo em restaurantes self services de Aracaju/SE
}

\author{
Mônica Cristina Rovaris Machado \\ Doutoranda em Administração pela Universidade do Vale do Itajaí - UNIVALI \\ Professora da Universidade Federal de Sergipe - UFS \\ Avenida Marechal Rondon, s/no. Jardim Rosa Elze. Cidade Universitária. Professor \\ José Aloísio de Campos. São Cristovão/ SE. CEP: 49100-000 \\ E-mail:monica.rovaris@ig.com.br \\ Milena Pinheiro da Silva \\ Pós-graduação em Finanças, Auditoria e Controladoria pela Universidade Tiradentes \\ Av. Murilo Dantas, 300. Farolândia. Aracaju. Sergipe/SE. CEP: 49032-490 \\ E-mail:milena.spinheiro@gmail.com
}

\section{RESUMO}

Esse estudo objetivou compreender como os custos que incidem sobre o produto e o serviço oferecido pelos restaurantes self services de Aracaju/SE influenciam na determinação de preços e quais os métodos de precificação usados para que a precificação seja feita. Para tanto, foi realizado um estudo qualitativo, de caráter exploratório-descritivo realizado mediante pesquisa de campo, e como ferramenta de coleta de dados foram utilizadas entrevistas estruturadas com questões abertas e fechadas. Além da formação do preço, tornou-se necessário analisar aspectos como a concorrência, os clientes e a gestão de custos, visto que estes fatores se destacam como ferramentas importantes para as organizações, pois permitem avaliar seus próprios limites e estabelecer parâmetros de organização. Assim, se investigou como as empresas formam seus preços, quais os componentes da estrutura dos custos e despesas, quais os métodos de custeio adotados e identificados falhas e benefícios nas empresas pesquisadas. Como resultado obteve-se que as empresas reconhecem a importância de adotar um método de custeio adequado para o processo de formação de preços, além de empregarem diversas metodologias para estabelecer o preço final ao consumidor, como as baseadas nos custos, concorrência e valor percebido.

Palavras-chave: Precificação. Custos. Restaurantes.

Costs and pricing: a study in self service restaurants of Aracaju / SE

\section{ABSTRACT}

This study aimed to understand how the costs related to the product and service offered by self services restaurants of Aracaju/SE influence on the pricing and which pricing methods are used. To this end, we conducted a exploratory and descriptive qualitative 
study, using a field research and as a tool for data collection were used structured interviews with open and closed questions. Besides the pricing, it became necessary to consider aspects such as competition, customers and management costs, as these factors stand out as important tools for organizations as they allow evaluating their own limits and establish parameters of organization. Thus, we investigated how companies formed the price, which components of the structure of costs and expenses, which the costing methods adopted and identified flaws and benefits in the companies surveyed. As a result it was found that companies recognize the importance of adopting a costing method suitable for the process of price formation, and employ different methodologies to establish the final price to the consumer, such as cost-based competition and perceived value.

Keywords: Pricing. Costs. Restaurants.

\section{INTRODUÇÃO}

A formação de um preço de venda para produtos e/ou serviços é uma tarefa significativa enfrentada pelos administradores nas organizações. Uma adequada definição do preço de venda proporciona à empresa lucratividade e retorno do capital investido e permite, ainda, a sobrevivência e o crescimento da mesma, tornando-a mais competitiva num mercado cada vez mais exigente.

A fim de suprir as necessidades e os desejos dos consumidores e como consequência aumentar a competitividade dos negócios, a determinação de preço assume um caráter estratégico, pois permite conciliar o posicionamento competitivo da empresa com a percepção de valor de seu público-alvo.

Para formar o preço de venda, torna-se necessário conhecer um conjunto de variáveis que servem de base no momento de sua elaboração e que exercem influências internas e externas à organização. Com relação às variáveis internas, ressaltam-se as estratégias, como: o posicionamento mercadológico escolhido pela empresa, a estrutura organizacional, os fatores financeiros e operacionais da entidade, a capacidade e nível de produção, as metas de crescimento e a estrutura dos custos e despesas, sendo esta última o foco desse trabalho. Nos aspectos externos é importante o conhecimento sobre o mercado em que a empresa está atuando, a demanda 
desejada dos produtos e/ou serviços, o valor percebido pelo cliente, as políticas governamentais, entre outros.

Constata-se, ainda, a importância na utilização de métodos para a determinação de preços de venda de uma maneira apropriada, em que a venda traga resultados satisfatórios, cobrindo os custos e despesas diretas e indiretas. Soma-se a isso a margem para o retorno do capital investido, visto que o entendimento da política de preços está se tornando um dos fatores preponderantes de competição entre as organizações.

Devido à importância da precificação para as empresas, nesse estudo são examinados os custos que incidem sobre o preço e os métodos disponíveis no mercado, aplicando os conhecimentos obtidos no setor de restaurantes do tipo self service.

\section{REFERENCIAL TEÓRICO}

\subsection{Preço e Valor}

Para Bruni e Famá (2011) o preço pode ser conceituado como a quantia recebida pelas organizações em virtude da oferta dos seus bens e/ou serviços, sendo estipulada por um valor satisfatório que permita cobrir os custos e a lucratividade. É, ademais, considerado o único elemento do marketing que gera receitas, enquanto que os demais causam custos, além de ser o mais flexível dada a possibilidade de poder ser modificado rapidamente sempre que necessário ou conveniente (KOTLER, 1998).

Por refletirem o resultado do efeito da produção das organizações, os preços podem ser associados a um indicativo de controle da eficiência dos bens e serviços fabricados, de modo que quanto mais lucrativo é um bem ou serviço, mais a organização se sente satisfeita no exercício de suas atividades (DUBOIS; KULPA; SOUZA, 2009).

Dubois, Kulpa e Souza (2009) compreendem o valor como um aspecto subjetivo e individual na ótica do consumidor, já que depende do grau de utilidade que o mesmo 
terá para a pessoa que o adquire. Assim, Bernardi (2009) o conceitua como o preço que o mercado está disposto a pagar para adquiri-lo.

Nota-se, portanto, que existe uma grande diferença entre valor e produto. E é nesse sentido que Bernardi (2009) alerta ser preciso encontrar um ponto de equilíbrio entre valor e preço. Tal problema só é resolvido a partir do momento em que a organização identifica e avalia o que afeta a percepção de valor para o mercado.

Para Bruni e Famá (2011), o preço precisa estar limitado entre o custo e o valor. Custo, devido aos gastos decorridos na empresa para poder ofertar o produto ou o serviço; e o valor consiste nos aspectos desejados pelos clientes e atendidos pelos produtos ou serviços. Ainda conforme esses autores, nenhuma empresa oferecerá um serviço ou produto por um preço inferior aos seus custos, do mesmo modo que os consumidores só pagarão por um produto ou serviço quando o valor percebido for superior.

De forma sucinta, Bruni e Famá (2011, p. 290) afirmam que "falar em preço é, ao mesmo tempo, analisar custos e estimar fatores intrínsecos do mercado em que o produto ou serviço será ofertado". Assim, da diferença entre o custo e o preço transcorre o lucro desejado pelas organizações e da diferença entre o preço e o valor decorrem os benefícios extras desejados pelos consumidores.

\subsection{Formação do Preço de Venda}

De acordo com Assef (2011), uma correta definição de preço é importante para a sobrevivência e o crescimento auto-sustentável de toda organização, independente de seu porte ou de sua área de atuação. Para o autor, as empresas precisam adotar uma política de preço eficiente, pois só assim conseguirão atingir os seus objetivos de lucros, se desenvolver a longo prazo, aumentar a quantidade de colaboradores e ofertar um atendimento qualificado aos seus clientes, entre outras melhorias.

Para Bruni e Famá (2011), a atividade de formação de preço é considerada como a verdadeira "arte do negócio", visto que o sucesso empresarial pode até não ser consequência de uma adequada formação de preço, porém a condução do mesmo de maneira inapropriada poderá levar ao insucesso da entidade. 
Considerando a formação de preço, os autores ainda ressaltam que esta está relacionada às exigências do consumidor, à existência de substitutos a preços mais competitivos, ao mercado de atuação do produto, à demanda desejada, ao domínio dos preços impostos pelo governo, e à capacidade de produção. É nesse sentido que os autores ainda fazem referência que o preço de venda deve ser imposto com base em um valor que permita a maximização dos lucros, mantenha a qualidade, atenda aos desejos do mercado atuante e melhor aproveite os níveis de produção.

Para Kotler (1998), a entidade precisa definir o que deseja realizar com o preço a ser aplicado e como pretende se posicionar perante o mercado. Somando-se a isso, Las Casas (2006) pontua que os administradores precisam determinar onde a organização pretende chegar com a política empregada, por isso é fundamental determinar objetivos de preços.

Acrescentando a este raciocínio, Bernardi (2009, p. 126) argumenta que "quanto mais congruente à estratégia de marketing, ao mercado escolhido, ao composto de marketing, aos objetivos da empresa e ao posicionamento pretendido" mais transparente os objetivos do preço e o processo restante.

Estabelecer uma política de preço, segundo Bernardi (2009, p. 122) é um assunto de vital importância para a organização, pois exige um alto grau de complexidade e responsabilidade. Desse modo, fatores mercadológicos, tributários, financeiros e econômicos devem ser levados em consideração na formação do preço de venda dos produtos e serviços, pois estes influenciam diretamente no processo e devem ser incorporados ao preço dos produtos a fim de obter o lucro e o sucesso desejado (ASSEF, 2011).

\subsection{Métodos de Formação de Preço}

Ao determinar um método de formação de preço, a organização precisa buscar um "preço específico ou possível que a direcione a um ponto em que demanda, preço e retorno se equilibrem" (BERNARDI, 2009, p. 130). Os principais métodos de determinação de preços se baseiam em: concorrência, custos e valor percebido pelo cliente (consumidor). 


\subsubsection{Preços baseados na concorrência}

Esse método é também chamado de preço de mercado e normalmente é usado quando a entidade baseia seus preços em relação aos preços cobrados pela concorrência, apresentando, assim, um menor cuidado quanto aos custos ou à demanda (KOTLER, 1998).

Nesta metodologia, Bruni e Famá (2011) ressalvam também que as empresas dão pouca atenção aos custos e à demanda, pois é a concorrência quem determina os preços a serem praticados. Esse valor pode ser determinado de duas formas: (1) consideração do preço da oferta: quando a organização forma seus preços cobrando mais ou menos que a concorrência; (2) através do preço da proposta: quando a empresa determina os seus preços por meio do seu julgamento de como será a atuação da concorrência para fixar preços.

Analisar a forma de prática dos concorrentes, para Bernardi (2009), é um auxílio na fixação de preço. Porém, isto só é possível mediante a solidez e a compatibilidade dos elementos referenciais, ou seja, dos itens do composto de marketing, dos custos, da qualidade, do porte da empresa, entre outros.

A aplicação do preço com base na concorrência, argumenta Kotler (1998, p. 447), é bastante popular e essa é uma boa solução quando os "custos são de difícil mensuração ou a resposta dos concorrentes é incerta", pois "reflete o conhecimento coletivo do setor, à medida que proporciona um retorno justo e não prejudica a harmonia entre as empresas".

\subsubsection{Preços baseados no valor percebido}

Nesse método as empresas devem procurar descobrir quais os valores que os clientes tendem a priorizar e tentar oferecê-los da maneira mais eficaz e eficiente possível (LAS CASAS, 2006).

Percebe-se, segundo Chang (1993 apud KOTLER, 1998, p. 445), que muitas empresas vêm utilizando este método para definir seus preços, visto que estas organizações "vêem as percepções de valor dos compradores, não seus custos, como 
fatores-chave para determinar seus preços". A fim de estimular os compradores elas usam variáveis relacionadas a preços no composto de marketing.

Segundo Bruni e Famá (2011), nesse tipo de metodologia as empresas empregam as percepções que os consumidores possuem do valor do produto, não os custos da produção. Este autor ainda salienta que preços são definidos para se ajustar aos valores percebidos.

\subsubsection{Preços baseados nos Custos}

Conforme Bruni e Famá (2011), diversos são os motivos que justificam a utilização deste método, sendo eles: (1) simplicidade: quando se ajusta o preço aos custos, não é necessário ajustá-los à demanda; (2) segurança: os vendedores são mais seguros acerca dos custos do que a respeito da concorrência e da demanda; (3) justiça: para alguns, um preço baseado nos custos é mais justo para os consumidores e para os vendedores.

Em adição, Bernardi (2009) relata que este método é o mais utilizado, e além do aspecto da simplicidade, mais quatro aspectos devem ser levados em consideração: (1) preço e sobrevivência: a determinação de preço deve garantir o lucro e o retorno sobre o investimento, caso um determinado volume de vendas do serviço ou produto seja atingido; (2) competitividade: o entendimento dos próprios custos e das despesas auxilia na compreensão dos custos dos concorrentes e da estratégia competitiva; (3) rotinização das decisões: com os aspectos básicos para a formulação de preços definidos, a execução da atividade torna-se sistematizada, consequentemente, serão despendidos mais esforços e tempo nos pontos políticos e estratégicos; e (4) estrutura de preço: em resumo, a formação de preço baseada nos custos é resultado da aplicação de um índice sobre os custos e as despesas, conhecido como mark-up (que significa "ponto de marcação").

Segundo Bernardi (2009, p. 164), o mark-up pode ser conceituado como "um índice ou percentual que irá adicionar-se aos custos e despesas, o que não significa dizer que deva ser aplicado linearmente a todos os bens e serviços”. Na prática, confunde-se mark-up com lucro de venda, o que é, além de um erro, é maléfico à 
organização, enfatiza Bernardi (2009). A fim de complementar este raciocínio, Braga (2010) menciona que mark-up se difere de lucro, visto que o lucro é uma parte da estrutura do mark-up.

De acordo com Braga (2010), a estrutura do mark-up é composta pelos seguintes itens: impostos e taxas que reflitam sobre o preço; comissões; lucro almejado; outras despesas que estejam vinculadas com o preço (que possam ser definidas como percentagens); despesas administrativas (que possam ser transformadas em percentagens).

De uma maneira geral, Bruni e Famá (2011) expressam que para a obtenção do mark-up se faz necessário descobrir o valor da margem ou preço de venda, descrita na fórmula a seguir:

$$
\begin{gathered}
G+(I \times P V)+(L \times P V)=P V \\
\text { onde: } \\
G=\text { gastos; } \\
I=\text { impostos; } \\
L=\text { lucro; } \\
P V=\text { preço de venda. }
\end{gathered}
$$

Para Braga (2010) existem dois tipos de mark-up: mark-up multiplicador e markup divisor, assim denominado porque se divide o custo por ele a fim de obter o preço de venda e aquele é assim denominado, porque multiplica o custo por ele com o intuito de obter o Preço de Venda. Ambos são apresentados a seguir:

$$
\begin{gathered}
\text { Mark-up divisor }=1-\text { margem } \\
\text { Mark-up multiplicador }=1 / 1-\text { margem }
\end{gathered}
$$

Uma das limitações do uso do mark-up pontuada por Bernardi (2009), é que esse método não envolve as despesas nem os impostos que incidirão sobre o preço de venda; e também não fornece o valor do lucro que a organização pretende obter. 
Entretanto, este permite uma simplificação no processo de formação de preços, ao passo que os custos e os demais gastos são embutidos no percentual do mark-up (BRUNI; FAMÁ, 2011).

Os principais métodos do processo de formação de preços de vendas baseados nos custos são aqueles que envolvem o custo pleno, custo de transformação, custo marginal, taxa de retorno exigida sobre o capital investido e custo padrão, descritos no quadro a seguir:

\begin{tabular}{|c|c|}
\hline Preços com base no custo pleno & $\begin{array}{l}\text { Nesse sistema os preços são determinados baseando-se nos } \\
\text { custos integrais: custos totais de produção acrescidos das } \\
\text { despesas de vendas, de administração e da margem de lucro } \\
\text { desejada. }\end{array}$ \\
\hline $\begin{array}{l}\text { Preços com base no custo de } \\
\text { transformação }\end{array}$ & $\begin{array}{l}\text { Esse método propõe-se a formar preços com base nos } \\
\text { custos de transformações, não considerando apenas os } \\
\text { custos com materiais diretos. }\end{array}$ \\
\hline Preços com base no custo marginal & $\begin{array}{l}\text { O custo marginal corresponde aos custos que não seriam } \\
\text { ocorridos caso um produto fosse excluído. }\end{array}$ \\
\hline $\begin{array}{l}\text { Preços com base na taxa de } \\
\text { retorno exigida sobre o capital } \\
\text { investido }\end{array}$ & $\begin{array}{l}\text { Baseia-se em uma taxa predeterminada de lucro sobre o } \\
\text { capital investido. A fórmula empregada para a obtenção do } \\
\text { preço de venda é } \mathrm{P}=(\mathrm{CT}+\mathrm{R} \times \mathrm{Cl}) / \mathrm{V} \text {, onde } \mathrm{CT} \text { são os } \\
\text { custos totais, } \mathrm{R} \text { é o lucro percentual desejado, } \mathrm{Cl} \text { o capital } \\
\text { investido e } \mathrm{V} \text { o volume de vendas. }\end{array}$ \\
\hline Preços com base no custo padrão & $\begin{array}{c}\text { Precisa separar os custos variáveis dos fixos para encontrar } \\
\text { o custo padrão, contudo eventuais erros entre o custo real e } \\
\text { o custo padrão devem ser corrigidos. }\end{array}$ \\
\hline
\end{tabular}

Quadro 01: Métodos do processo de formação de preços de vendas baseados nos custos Fonte: Santos (1994 apud BRUNI ; FAMÁ, 2011).

\subsection{Métodos de custeio}

De acordo com Dubois, Kulpa e Souza (2009, p. 128) custeio é "o ato ou efeito de custear", logo, o termo custeio pode ser correlacionado como "uma forma de apropriar custos".

Para Bernardi (2009), adotar um método de custeio está relacionado com os objetivos da empresa. Nesse contexto, Dubois, Kulpa e Souza (2009) mencionam que todos os métodos de custeio têm como objetivo determinar o custo unitário de cada produto ou serviço, e para isto se faz necessário mensurar os custos diretos (formado pelas matérias-primas, embalagens, componentes adquiridos prontos e outros materiais utilizados no processo de fabricação, que podem ser associados diretamente ao produto) e 
indiretos (custos apropriados de forma indireta ao produto, tais como mão de obra indireta, seguros, aluguel de fábrica, supervisão de linha, depreciação dos equipamentos, entre outros.

\subsubsection{Método de custeio por absorção}

Esse método de custeio envolve todos os custos diretos e indiretos, fixos e variáveis de uma produção. A principal finalidade é mensurar os estoques, utilizados como parâmetro para a formação de preços. Conforme Bernardi (2009), quatro pontos devem ser ponderados ao adotar este método de custeio: o volume de produção; métodos de rateio dos custos indiretos e fixos, para gerar distorções; capacidade da fábrica; níveis de produtividade e eficiência.

Para aplicar o método do custeio por absorção três passos devem ser seguidos, afirma Martins (2008): (1) separação entre custos e despesas: as despesas não entram no custo da produção; (2) apropriação dos custos diretos: através da verificação dos custos que são atribuídos diretamente ao produto; (3) apropriação dos custos indiretos: diante da situação que estes custos não são identificáveis é necessário alocá-los aos produtos ou serviços.

Entre as vantagens de utilizar o método do custeio por absorção, considera-se o fato de que o mesmo é oficialmente aceito (LEONE, 2009). As disposições legais são unânimes ao tratar da apuração dos custos através deste critério. Ressalta ainda o autor, que dois dos diplomas legais mais importantes (a Lei das Sociedades por Ações e o Regulamento do Imposto de Renda) obrigam a utilizar este método, mesmo que seja de forma parcial.

\subsubsection{Método de custeio variável ou direto}

O método do custeio variável, como define Dubois, Kulpa e Souza (2009, p. 133), "é aquele no qual os custos fixos são alocados aos resultados como se fossem despesas, enquanto os custos e as despesas variáveis são elementos fundamentais para obtenção da Margem de Contribuição". 
Com base em Martins (2008, p. 198), no custeio variável, "só são alocados aos produtos os custos variáveis, ficando os fixos separados e considerados como despesas do período, indo diretamente para o resultado; para os estoques só vão, como consequência, custos variáveis".

A utilização deste método gera vantagem no sentido de utilizar o conceito de Margem de Contribuição, visto que este é um elemento importante para a tomada de decisão. Para obter a Margem de Contribuição subtraem-se do preço de venda os custos e as despesas variáveis (DUBOIS, KULPA; SOUZA, 2009, p. 133), conforme descrito a seguir:

$$
M C=P V-C V
$$

É através da Margem de Contribuição que será identificado no portfólio de produtos aqueles que devem ser conservados, modificados ou eliminados. Os resultados da Margem de Contribuição determinam quais as condições de venda que devem ser implementadas, o nível da concorrência ou se o mercado atende ao preço estabelecido (ASSEF, 2011).

As vantagens do custeio variável são apresentadas por Dubois, Kulpa e Souza (2009): extinção das variações nos resultados provenientes das quantidades produzidas e vendidas; facilidade em obter a margem de contribuição; maximização da margem de contribuição, conforme a visualização dos produtos com maior margem de contribuição unitária; auxílio na tomada de decisão; ajuda no entendimento do processo de custeio dos produtos; possibilidade de uma maior clareza no planejamento do lucro e na tomada de decisão; permissibilidade de os gerentes avaliarem o desempenho da organização. Entre as desvantagens, ainda aborda Dubois, Kulpa e Souza (2009): dificuldade de segregação entre os custos fixos e variáveis; o método fere os princípios contábeis. 


\subsubsection{Método de custeio baseado em atividades (ABC)}

Os métodos de custeio abordados anteriormente são os tradicionais, que tem como foco a valorização da produção, do produto e dos estoques. Contudo, devido à globalização da economia e à crescente tecnologia aplicada na fabricação de produtos, os custos indiretos de fabricação se tornaram mais relevantes (BERNARDI, 2009).

A eterna procura pelo menor preço sem interferir na funcionalidade e na qualidade dos bens e serviços, deve ser um objetivo permanente da empresa, como salienta Bernardi (2009). É nesse processo de evolução gradativa que a literatura passou a dar ênfase aos mecanismos de formação de custos (BRUNI; FAMÁ, 2011).

Catelli e Guerreiro (1994 apud LEONE, 2009) mencionam que ABC é o custeio baseado em atividades, cujo sistema parte da premissa que as diversas atividades executadas na empresa geram custos e que os vários produtos utilizam destas atividades.

A metodologia aplicada no método de custeio ABC é descrita por Martins (2008, p. 93) como: a) Identificação das atividades relevantes: nessa etapa as atividades relevantes ao processo da produção são selecionadas; b) Atribuição de custos às atividades: nessa fase os custos serão atribuídos às atividades. Tais associações podem ser feitas através da alocação direta (quando há uma identificação de forma precisa dos itens dos custos com as atividades), rastreamento (quando ocorre uma relação de causa e efeito entre a execução da atividade e a geração de custos) e rateio (quando não existe a possibilidade de utilizar as outras duas formas de atribuição); c) Identificação e seleção dos direcionadores de custos: os "direcionadores de custos" são selecionados mediante o que estabelece uma melhor relação dos custos das atividades com o produto. Direcionador de custos é "o fator que determina o custo de uma atividade"; d) Atribuição dos custos dos recursos às atividades no modelo apresentado: as atividades executadas pelo departamento são custeadas por meio dos "direcionadores de custos de recursos"; e) Atribuição dos custos das atividades aos produtos: os custos das atividades são atribuídos através dos direcionadores de custos. 
Esse método apresenta duas limitações, explicam Dubois, Kulpa e Souza (2009), os altos custos administrativos devido aos diversos centros de atividades e geradores de custos, e também a existência de algumas alocações que são inevitáveis.

\subsection{Restaurantes e precificação}

De acordo com Freund (2008) o principal produto dos restaurantes é o serviço, pois além de oferecer alimentos e bebidas, vende-se competência e profissionalismo, calor humano e cordialidade; e que mesmo aparentando ser subjetivo e sem parâmetros de medidas, é perfeitamente mensurável pelos clientes.

Conforme Kotler (1998, p. 383), produto é algo que pode ser oferecido a um mercado para satisfazer a um desejo ou necessidade, e serviço é "qualquer ato ou desempenho que uma parte possa oferecer a outra e que seja essencialmente intangível e não resulte na propriedade de nada". Sua produção pode ou não estar vinculada a um produto físico (KOTLER, 1998). Para Rathmell (1966 apud LAS CASAS, 2006, p. 17), serviço é considerado como sendo "um ato, uma ação, um esforço, um desempenho". $\mathrm{Na}$ visão de Kotler (1998), uma oferta de mercado de uma organização agrupa alguns serviços - sendo que o componente serviço pode, ou não, ser a parte mais importante da oferta.

Segundo Lobo (2009) existe vários tipos de linha de atuação de restaurantes, como: cozinha internacional, fast food, massas e pizzas, churrascaria, vegetariano, típico, a peso, entre outros. E dentro dessas linhas pode-se trabalhar com o sistema à la carte ou self service.

Para o Serviço Nacional de Aprendizagem Nacional (SENAC, 2008) o sistema à la carte é o mais tradicional, e neste tipo de serviço o cardápio (menu) é apresentado ao cliente com a relação de todas as opções de pratos e bebidas disponíveis. Com base nos itens destacados no cardápio é que o cliente faz o seu pedido, que é anotado pelo garçom e encaminhado para a cozinha para que os pratos sejam preparados.

Ainda conforme o Serviço Nacional de Aprendizagem Nacional (SENAC, 2008), os preços praticados nestes restaurantes, geralmente, são mais elevados, pelo fato de oferecer um serviço personalizado, com pratos preparados ao gosto do cliente. Além 
deste aspecto, nota-se que em restaurantes à la carte é necessário um maior número de colaboradores a fim de agilizar a elaboração de guarnições e as pequenas adaptações solicitadas pelos clientes.

De acordo com o Serviço de Apoio às Micro e Pequenas Empresas (SEBRAE, 2010) os restaurantes que aplicam o sistema self service são empreendimentos característicos do mundo moderno, que se adaptaram as exigências dos consumidores que vivem a correria diária dos grandes centros urbanos. O sistema de pesagem utilizado nestes restaurantes conquista a simpatia do cliente, pois permite que os mesmos possuam uma comida nutritiva, bem-feita e variada, tendo a possibilidade de escolher os alimentos para a sua refeição e na quantidade desejada.

Independente da linha de atuação, o que define um bom desempenho de um restaurante é o conceito de bom no mercado, a identificação dos perfis de seus clientes, tipos de serviços oferecidos, horários de atendimento, o layout, além da qualidade com preços que sejam acessíveis para o consumido. (VENTURI; LENZI, 2004).

O cálculo correto do preço é fundamental para a saúde financeira da empresa, pois este deve ter como principal base a ficha técnica, onde todos os componentes do prato são relacionados, com as suas respectivas quantidade e custos, e a partir do custo do prato calcular o preço (FREUND, 2008).

Para o Serviço Nacional de Aprendizagem Nacional (SENAC, 2008) os pontos que precisam ser considerados para o processo de formação de preço são: o preço que o cliente estaria disposto a pagar, o preço praticado pela concorrência, os custos administrativos, os preços dos fornecedores de matéria-prima e tempo de montagem, embalagem ou preparo.

Estabelecido o primeiro patamar de preço (o preço que o cliente estaria disposto a pagar) é preciso verificar se ele é suficiente para permitir à empresa uma margem de lucro que seja satisfatória. Acrescentando este raciocínio, Freund (200, p. 197) explica que o preço final só poderá ser fechado depois de uma pesquisa junto aos principais concorrentes, definição do espaço que o restaurante deseja ocupar no mercado gastronômico e o público que pretende atingir. Este autor, também, revela que "de nada 
adianta ter um cardápio com o custo ideal, se o preço de venda está muito abaixo ou acima da concorrência".

Sendo assim, estabelecer uma estratégia e uma política de preço que seja bem sucedida é um dos assuntos críticos e vitais para qualquer empresa, e para isso uma política de preços é sustentada por dois fatores: estratégia mercadológica e uma coordenação sistêmica e integrada (BERNARDI, 2009).

\section{PROCEDIMENTOS METODOLÓGICOS}

\subsection{Caracterização do estudo}

No que concerne à caracterização da pesquisa, esta se configura como qualitativa. Esta abordagem justifica-se em virtude da necessidade de uma investigação aprofundada da metodologia aplicada para o processo de precificação dos restaurantes self service do centro de Aracaju, SE.

A pesquisa classifica-se como exploratório-descritiva, com relação aos fins. Para Gil (2008, p. 27), o caráter exploratório tem a intenção de "desenvolver, esclarecer e modificar conceitos e ideias, objetivando a elaboração de problemas mais precisos", logo, a pesquisa pode ser assim considerada, devido ao fato de pretender ampliar o conhecimento sobre formação de preços. No entanto, o estudo almeja descrever "as características da determinada população ou fenômeno ou o estabelecimento de relações entre variáveis"; nesse caso sobre os restaurantes do centro de Aracaju, SE. Com relação aos meios de investigação, esta se configura como pesquisa de campo. O enfoque bibliográfico está presente nas duas primeiras etapas, visando fundamentar teoricamente o estudo.

É, nesse sentido, de analisar a metodologia de precificação adotada pelos restaurantes, que foram selecionados cinco restaurantes que adotam o sistema self service e atuam na região central de Aracaju, SE.

\subsection{Fontes de evidências utilizadas}

Conforme Yin (2005, p. 116), dentre as fontes de evidências, a entrevista é uma das mais importantes. Para Lakatos e Marconi (2010) a entrevista é um procedimento 
utilizado na investigação social para a coleta de dados ou no intuito de ajudar no diagnóstico ou no tratamento de um problema social. Ainda, do ponto de vista destas autoras a entrevista acontece através de uma conversação face a face, de maneira metódica, o que proporciona ao entrevistado, verbalmente, a informação necessária.

As entrevistas podem assumir três formas: espontânea - questionando ao entrevistado fatos que permitem que expresse sua opinião; focal - apresenta um caráter informal e espontâneo com um conjunto de perguntas apenas para confirmar fatos que já tenham sido estabelecidos anteriormente; e levantamento formal - é feito através de questões estruturadas, com o objetivo de levantar informações (YIN, 2005).

A técnica escolhida na pesquisa foi a de entrevista estruturada, composta por questões abertas e fechadas. A sua aplicação se deu no período de 31 de junho de 2011 até 17 de setembro de 2011.

\subsection{Categorias e elementos de análise}

As entrevistas foram gravadas, transcritas e analisadas conforme as categorias e elementos de análise dispostos no quadro a seguir:

\begin{tabular}{|c|c|c|}
\hline Questões de Pesquisa & Categorias Analíticas & Elementos de Análise \\
\hline $\begin{array}{c}\text { Qual a estrutura de custos das } \\
\text { empresas pesquisadas que } \\
\text { reflete na determinação de } \\
\text { preços? }\end{array}$ & $\begin{array}{c}\text { Estrutura dos custos e } \\
\text { despesas }\end{array}$ & $\begin{array}{c}\text { Matéria prima } \\
\text { Mão de obra direta }\end{array}$ \\
\hline $\begin{array}{c}\text { Quais os métodos de } \\
\text { precificação adotados pelos } \\
\text { restaurantes de Aracaju, SE? }\end{array}$ & Determinação dos preços & Método de apropricação aplicado; \\
\hline $\begin{array}{c}\text { Quais os benefícios e falhas } \\
\text { diagnosticados pelas } \\
\text { empresas com relação à } \\
\text { metodologia aplicada? }\end{array}$ & Monitoramento e controle & $\begin{array}{c}\text { Custos; } \\
\text { Valor percebido pelos clientes; } \\
\text { Concorrência. }\end{array}$ \\
\hline
\end{tabular}

Quadro 02: Categorias e elementos de análise Fonte: Elaborado pelas autoras (2011). 


\section{APRESENTAÇÃO DOS RESULTADOS}

\subsection{Caracterização dos Restaurantes Self Service}

Nesta seção apresenta-se um breve perfil dos restaurantes self service situados no centro da Cidade de Aracaju (SE). Para caracterizar as empresas foram analisados os seguintes itens: tempo de atuação, número de sócios, formação dos sócios, número de funcionários, capacidade e rotatividade do restaurante e o faturamento mensal.

Tabela 01: Características dos restaurantes self service

\begin{tabular}{|c|c|c|c|c|c|}
\hline Empresa & A & B & C & D & E \\
\hline Tempo de atuação & 11 anos & 10 anos & 14 anos & 11 meses & $\begin{array}{c}1 \text { ano e } \\
\text { meses }\end{array}$ \\
\hline Números de sócios & 2 sócios & 1 sócio & 5 sócios & 2 sócios & 2 sócios \\
\hline $\begin{array}{c}\text { Qualificação dos } \\
\text { sócios }\end{array}$ & $\begin{array}{c}\text { Superior } \\
\text { Fundamental }\end{array}$ & Superior & $\begin{array}{c}\text { Superior } \\
\text { Fundamental } \\
\text { Técnico }\end{array}$ & Fundamental & Médio \\
\hline $\begin{array}{c}\text { Número de } \\
\text { funcionários }\end{array}$ & 20 & 14 & 14 & 7 & 7 \\
\hline $\begin{array}{c}\text { Capacidade do } \\
\text { restaurante }\end{array}$ & 280 lugares & 90 lugares & 100 lugares & 80 lugares & 94 lugares \\
\hline $\begin{array}{c}\text { Rotatividade do } \\
\text { restaurante }\end{array}$ & 800 pessoas & 150 & - & 180 pessoas & 140 pessoas \\
\hline $\begin{array}{c}\text { Preço do Quilo } \\
\text { pessoas }\end{array}$ & 12,49 & 14,99 & 27,00 & 12,99 & 24,90 \\
\hline $\begin{array}{c}\text { Faturamento } \\
\text { Mensal }\end{array}$ & 60 mil & 30 mil & - & 45 mil & 30 mil \\
\hline
\end{tabular}

Fonte: Dados da Pesquisa (2011).

No quesito tempo de atuação, é possível observar que a empresa $C$ é a mais antiga pois está no mercado há 14 anos; as empresas $A$ e $C$ têm, respectivamente, 11 e 10 anos de atividade; e as empresas D e E são mais recentes.

Questionou-se, ainda, sobre a quantidade de funcionários que trabalham nos restaurantes self service. As informações obtidas revelam que a empresa $A$ conta com 20 funcionários; as empresas $B$ e $C$ contam com 14 funcionários cada; e as empresas $D$ e E mantém 7 funcionários, cada. 
Os restaurantes estudados possuem em média 2 sócios ( $A, D$ e $E$ ), porém o restaurante $C$ possui 5 sócios e o $B$ apenas um sócio. Nos restaurantes mais antigos ( $A, B$ e $C$ ) são encontrados sócios com formação superior; no restaurante $E$ o sócio tem ensino médio e no restaurante $\mathrm{D}$ o sócio tem formação fundamental.

Ao cruzar os dados sobre a capacidade e a rotatividade dos restaurantes estudados, chama a atenção 0 fato de que o restaurante $A$, que apresenta uma capacidade para 280 pessoas, consegue atender cerca de 800 clientes diariamente, ao passo que os restaurantes B e E possuem uma capacidade para 90 e 94, respectivamente, e conseguem atender uma demanda de 150 refeições, e o $D$ que apresenta estrutura para 80 lugares e recebe cerca de 180 consumidores por dia. Por fim, o respondente do restaurante $C$ informou não saber acerca da rotatividade, salientando apenas que possui lugares para 100 pessoas. Quanto ao faturamento mensal dos restaurantes, obteve-se a informação de que este oscila entre $R \$ 30.000,00$ e $R \$ 60.000,00$. O preço do quilo nos restaurantes varia de $R \$ 12,49$ a $R \$ 27,00$.

Examinando-se os preços praticados e a rotatividade nos restaurantes, constatase que quanto maior o preço praticado, menor é a demanda, mostrando o quão é importante considerar a lei da oferta e da procura que rege, conforme descrito por Dubois, Kulpa e Souza (2009), que a oferta pretende vender um bem praticando um preço maior e a demanda opta por adquirir um mesmo bem por um preço menor.

\subsection{Estrutura de Custos e Despesas}

Com relação à estrutura de custos e despesas dos restaurantes self service, três elementos básicos foram levados em consideração: matérias primas, mão de obra direta e custos indiretos de fabricação. As matérias-primas fazem parte dos custos diretos, e são chamados de material direto. O material direto é aquele formado "pelas matérias-primas, embalagens, componentes adquiridos prontos e outros materiais utilizados no processo de fabricação, que podem ser associados diretamente ao produto" (BRUNI; FAMÁ, 2011, p.43).

Normalmente as empresas empregam algum sistema para contabilizar os custos com os materiais comprados e, assim, poder repassar para o produto final. Esses 
métodos utilizam as quantidades de matérias primas adquiridas e o preço pago por estas - alguns chegam a utilizar apenas as principais matérias-primas de modo a facilitar o processo de elaboração do preço.

Diante disso, examinaram-se quais aspectos eram considerados importantes para a composição do custo das matérias-primas. Dentre os informados, verificou-se que todos os restaurantes $(A, B, C, D$ e E) consideram o valor referente ao preço pago de cada matéria-prima. Além disso, os gestores dos restaurantes $B$ e $E$ citaram as principais matérias primas utilizadas e o restaurante $B$ mencionou, também, sobre a quantidade de cada matéria prima utilizada no processo produtivo. O Quadro 03 apresenta os dados coletados.

\begin{tabular}{|c|c|}
\hline Elementos das matérias-primas & Restaurantes \\
\hline Valor referente ao preço pago de cada matéria-prima & A, B, C, D e E \\
\hline Principais matérias-primas utilizadas & B e E \\
\hline Quantidade de cada matéria-prima utilizada & B \\
\hline
\end{tabular}

Quadro 03: Elementos das matérias-primas

Fonte: Dados da Pesquisa (2011).

Além das matérias-primas, verificou-se a respeito da mão de obra direta. Os custos de mão de obra direta são aqueles que se referem às pessoas que estão vinculadas ao produto em elaboração, ou seja, referem-se à remuneração dos colaboradores da empresa (BRUNI; FAMÁ, 2011). Constatou-se que as cinco empresas utilizam o salário na composição do custo da mão de obra direta, e quatro (B, $C, D$ e E) consideram também os encargos envolvidos. Percebeu-se que nenhum restaurante utiliza as horas trabalhadas, nem o custo de serviço por hora como elemento da composição da mão de obra direta, conforme apontado no Quadro 04. 


\begin{tabular}{|c|c|}
\hline Mão-de-obra direta & Restaurantes \\
\hline Encargos & $\mathrm{B}, \mathrm{C}, \mathrm{D}$ e E \\
\hline Horas Trabalhadas por mês & - \\
\hline Custo do serviço por hora & - \\
\hline Salários & $\mathrm{A}, \mathrm{B}, \mathrm{C}, \mathrm{D}$ e E \\
\hline
\end{tabular}

Quadro 04: Mão de obra Direta

Fonte: Dados da Pesquisa (2011).

As empresas contabilizam o salário que corresponde à quantia recebida pelo funcionário por desempenhar determinada função e os encargos, os quais são decorrentes da legislação trabalhista.

Com relação aos custos indiretos de fabricação, as respostas obtidas foram bastante diversificadas. Verificou-se que os elementos contabilizados pelas empresas na composição dos custos indiretos de fabricação são: depreciação, nos restaurantes $A$ e $B$, energia elétrica nos empreendimentos, $C, D$ e E; materiais indiretos, no restaurante E; mão de obra indireta, nas empresas B e C; e, seguro, na empresa D. O Quadro 05 explana os dados recolhidos:

\begin{tabular}{|c|c|}
\hline Custos Indiretos de Fabricação & Restaurantes \\
\hline Depreciação & A e B \\
\hline Energia elétrica & C, D e E \\
\hline Materiais indiretos & E \\
\hline Mão de obra indireta & A e B \\
\hline Seguro & D \\
\hline
\end{tabular}

Quadro 05: Custos indiretos de fabricação

Fonte: Dados da Pesquisa (2011).

Conforme visto no referencial teórico, as matérias-primas e a mão de obra direta fazem parte dos custos diretos, e estes são facilmente identificados, não precisando de métodos de rateio. Contudo, os custos indiretos de fabricação não são identificados diretamente em cada produto, necessitando assim de um método de rateio. Braga (2010) ressalva acerca da necessidade de utilizar uma base de rateio justa, visto que 
erros podem acontecer. Normalmente, as empresas utilizam três métodos para apuração dos custos, sendo eles: custeio por absorção, custeio direto e custeio baseado em atividades (ABC).

Ao se verificar o método utilizado nos restaurantes para a apropriação dos seus custos, apenas a empresa B informou que faz uso do método do custeio por absorção. Os restaurantes $A$ e $E$ não revelaram o método utilizado e os restaurantes $D$ e $C$ não utilizam qualquer método. Segundo Leone (2009), o método de absorção é o mais utilizado entre as empresas, pois busca atender à legislação fiscal. Ademais, esse método define que o custo do produto deve cobrir os custos totais, ou seja, a matériaprima consumida, mão de obra direta e os custos indiretos alocados.

\subsection{Determinação do Preço}

$\mathrm{Na}$ literatura foi visto que existem três métodos principais para o processo de formação de preço, os quais envolvem custos, concorrentes e valor percebido pelo consumidor. Com isso, procurou-se saber acerca dos métodos aplicados pelos restaurantes self service do centro de Aracaju (SE). As respostas obtidas indicam que todos empregam os custos no processo de formação de preço, sendo que, além dos custos, três restaurantes (A, B e C) fazem uso do valor percebido pelo cliente e os restaurantes $B$ e $E$ analisam o preço da concorrência. No restaurante $D$ o preço é baseado unicamente nos custos. Os dados são visualizados no Quadro 06.

\begin{tabular}{|c|c|}
\hline Método de Formação de Preço & Restaurantes \\
\hline Baseado nos custos & D \\
\hline Baseado na concorrência & - \\
\hline Baseado no valor percebido & E \\
\hline Baseado nos custos e na concorrência & A e C \\
\hline Baseado nos custos e no valor percebido & - \\
\hline Baseado na concorrência e no valor percebido & B \\
\hline Baseado nos custos, concorrência e valor percebido & \\
\hline
\end{tabular}

Quadro 06: Métodos de formação de preço de venda

Fonte: Dados da Pesquisa (2011). 
De acordo com Bruni e Famá (2011), as empresas só conseguem permanecer e sobreviver no mercado se seus preços ultrapassarem os seus custos. Nos restaurantes examinados os preços se baseiam nos custos, confirmando que estes são fatores determinantes para o processo de determinação de preço, o que ratifica os resultados obtidos no estudo de Machado, Machado e Holanda (2006).

Conforme abordado no referencial teórico, Braga (2010) menciona que o método de formação de preço baseado nos custos é também conhecido como mark-up, e este, segundo Bernardi (2009, p. 164), é conceituado como "um índice ou percentual que irá adicionar-se aos custos e despesas, o que não significa dizer que deva ser aplicado linearmente a todos os bens e serviços". Foi indagado, também, junto aos gestores dos restaurantes que utilizam os custos como base no seu processo de formação do preço de venda, quanto era a margem utilizada. Apenas os entrevistados dos restaurantes $A$, D e E informaram que empregam uma taxa de mark-up de $30 \%$.

Verificou-se, ainda que a empresa B tem como base o custo pleno, ou seja, determinam os preços baseando-se nos custos integrais; custos totais de produção acrescidos das despesas de vendas, de administração e da margem de lucro (SANTOS 1994 apud BRUNI; FAMÁ, 2011) e o restaurante C estabelece seus preços com base numa taxa de retorno exigida sobre o capital investido, o qual, ainda de acordo com Santos (1994 apud BRUNI; FAMÁ, 2011), baseia-se em uma taxa predeterminada de lucro sobre o capital investido.

Percebeu-se, portanto, que as empresas A, B e C analisam, além dos custos, o valor percebido pelo cliente no processo de formação de preço. $O$ restaurante $D$ não tem conhecimento do valor percebido pelo cliente e o E procura saber apenas para ter ciência do que desejam seus consumidores. O Quadro 07 elucida as informações coletadas: 
Custos e precificação: um estudo em restaurantes self services de Aracaju/SE Mônica Cristina Rovaris Machado, Milena Pinheiro da Silva

\begin{tabular}{|c|c|}
\hline Preço praticado com base no valor percebido pelo cliente & Restaurantes \\
\hline Utiliza como base no processo de formação de preço & A, B e C \\
\hline $\begin{array}{c}\text { Oferece aos clientes o que é esperado por ele em termos de } \\
\text { qualidade e preço }\end{array}$ & A, B e C \\
\hline A nível de conhecimento & E \\
\hline Não tem conhecimento & D \\
\hline
\end{tabular}

Quadro 07: Preço praticado com base no valor percebido pelo cliente Fonte: Dados da Pesquisa (2011).

Nesse quesito, constatou-se que as empresas A, B e C estão em harmonia com a literatura, ao passo que, como Las Casas (2006) cita, as empresas necessitam descobrir quais os valores que os clientes priorizam, a fim de oferecê-los de maneira eficaz e eficiente.

De acordo com as informações coletadas, notou-se que as empresas $B$ e $E$ se baseiam na concorrência para determinar seus preços, porém, algumas outras empresas procuram saber os preços dos concorrentes apenas para ter ciência de como está o mercado da gastronomia. É com base nisso, que a empresa $A$ e $D$ não têm conhecimento dos preços dos concorrentes. Já o restaurante $C$ conhece no intuito de justificar seus preços aos clientes e comparar com o seu já determinado. As organizações B e E procuram conhecer para comparar com seus custos e utilizá-lo no processo de formação de preço. O Quadro 08 ilustra as informações.

\begin{tabular}{|c|c|}
\hline Preço praticado com base na concorrência & Restaurantes \\
\hline Utilizar no processo de formação de preço & B e E \\
\hline Justificar seus preços aos clientes & C \\
\hline Comparar com os seus custos & B e E \\
\hline Comparar com o seu já determinado & C \\
\hline Não tem conhecimento & A e D \\
\hline
\end{tabular}

Quadro 08: Preços praticados com base na concorrência Fonte: Dados da Pesquisa (2011).

A aplicação desse tipo de metodologia, argumenta Kotler (1998, p. 447), é uma boa solução quando os "custos são de difícil mensuração ou a resposta dos 
concorrentes é incerta", pois "reflete o conhecimento coletivo do setor, à medida que proporciona um retorno justo e não prejudica a harmonia entre as empresas".

\subsection{Monitoramento e controle}

Foi pesquisado a respeito do grau de satisfação dos gestores em relação ao método de formação de preço praticado. De acordo com os dados coletados, foi detectado que dos restaurantes pesquisados, o A, C, D e E estão muito satisfeitos com a metodologia aplicada e o B apresenta-se satisfeito.

Os gestores foram indagados também sobre os benefícios que os restaurantes possuem com base na metodologia aplicada. Os gestores de três restaurantes ( $A, B$ e D) acreditam que o método é simples e prático; quatro ( $A, B, D$ e E) afirmam que ele proporciona facilidade e segurança; dois ( $C$ e $D$ ) informam que garante o lucro; dois ( $B$ e E) asseguram que ele garante competitividade; e, por fim, três (A, B e $C)$ argumentam que traz satisfação para os clientes. Isso pode ser visualizado no Quadro 09:

\begin{tabular}{|c|c|}
\hline Satisfação dos gestores com a metodologia & Restaurantes \\
\hline Simples e prático & A, B e D \\
\hline Facilidade e segurança & A, B, D e E \\
\hline Garante o lucro & C e D \\
\hline Proporciona a competitividade & B e E \\
\hline Gera satisfação dos clientes & A, B e C \\
\hline
\end{tabular}

Quadro 09: Benefícios em relação a metodologia aplicada Fonte: Dados da Pesquisa (2011).

O método traz benefícios, conforme visto no quadro, porém os gestores dos restaurantes detectaram que a metodologia aplicada apresenta falhas, sendo que nas empresas $A$ e $B$ não se utiliza sistema adequado e na empresa $D$ há o entendimento de que a existência de um profissional qualificado iria fazer o diferencial. $\mathrm{Na}$ mesma empresa não há um controle efetivo de todos os custos e despesas, existindo assim 
falhas em certas decisões. Em dois restaurantes (C e E) a metodologia não apresenta falhas. O Quadro 10 reúne esses dados.

\begin{tabular}{|c|c|}
\hline Falhas em relação a metodologia aplicada & Restaurantes \\
\hline Não possui um sistema adequado & A, B \\
\hline Falta de um profissional qualificado & D \\
\hline Falta de um controle efetivo dos custos & D \\
\hline Não apresenta falhas & C e E \\
\hline
\end{tabular}

Quadro 10: Falhas em relação à metodologia aplicada

Fonte: Dados da Pesquisa (2011).

Mesmo acreditando que não tenha falhas, é sabido que o ideal é que os gestores acompanhem o mercado e procurem oportunidades de diferenciação que sejam perceptíveis pelos consumidores para elaborar seus preços.

\section{CONSIDERAÇÕES FINAIS}

O estudo realizado permitiu constatar que em todos os restaurantes examinados o método de elaboração de preços é baseado nos custos. No restaurante $D$ há a utilização apenas desse método, sendo que nos demais são utilizados simultaneamente outros elementos. Alinhado a esse método, nos restaurantes $A$ e $C$ se agrega o valor percebido pelo cliente, no restaurante $E$ se acrescenta a metodologia baseando-se nos preços praticados pelos concorrentes e no restaurante $B$ considera-se tanto o valor percebido pelo cliente quanto a concorrência.

Autores consultados na elaboração do referencial teórico mencionam que a metodologia de precificação baseada nos custos e nos preços praticados pelo mercado é simples e prática, pois não exige muito tempo em pesquisas e análises do comportamento do consumidor, porém pode conduzir a erros, devido a não estar relacionada aos resultados finais da empresa. No estudo realizado, identificou-se que apenas no restaurante $B$ faz-se uso de uma conciliação entre os três métodos, a fim de 
obter um preço que seja fidedigno, ou seja, que permita que a empresa tenha o lucro desejado e atenda às necessidades e desejos dos consumidores.

Nesse sentido, pode-se afirmar que por ser o custo algo primordial na elaboração dos preços, os restaurantes estudados utilizaram-no como método principal, havendo, porém, a necessidade de considerar métodos que possam servir de complemento a esse, para garantir uma melhor precificação e, por conseguinte, maior controle do negócio.

Esse estudo apresenta limitações que devem ser ressaltadas. Primeiramente, a pesquisa se ateve a apenas um segmento de mercado, o da gastronomia, e se baseou apenas em cinco restaurantes localizados no centro de Aracaju, no Estado de Sergipe, cujos gestores se dispuseram a participar das entrevistas. Com isso, os resultados aqui encontrados são válidos unicamente para o contexto das empresas do ramo da gastronomia examinadas, sendo necessários outros estudos para realmente validar as conclusões acerca da metodologia aplicada nos restaurantes, tentando reunir o maior número possível de estabelecimento. Ainda como fator limitante pode se considerar a escassez de publicações científicas relacionada ao tema, especialmente no ramo da gastronomia.

A fim de contribuir para que novas pesquisas sejam desenvolvidas, torna-se relevante propor algumas sugestões que podem ser adotadas por futuros pesquisadores para ampliar os conhecimentos em relação ao tema estudado. Sendo elas: (1) elaboração de um roteiro para o processo de formação de preço de restaurantes self service; (2) aplicação de um estudo congênere nos demais restaurantes da área central, além disto, em empresas de médio e grande porte da região; e (3) estudos que busquem explorar como os custos afetam a determinação de preços em empresas em geral.

\section{REFERÊNCIAS}

ASSEF, R. (2011). Guia prático de formação de preços: aspectos mercadológicos, tributários e financeiros para pequenas e médias empresas. (4 ed.). Rio de Janeiro: Elsevier. 
BERNARDI, L. A. (2009). Manual de formação de preços: políticas, estratégias e fundamentos. (3 ed.). São Paulo: Ed. Atlas.

BRAGA, R. M. M. (2011). Gestão da gastronomia: custos, formação de preços, gerenciamento e planejamento do lucro. (2 ed.). São Paulo: Senac.

BRUNI, A. L.; FAMÁ, R. (2011). Gestão de custos e formação de preços: com aplicações na calculadora HP $12 C$ e Excel. (5 ed.). São Paulo: Atlas.

DUBOIS, A.; KULPA, L.; SOUZA, L. E. (2009). Gestão de custos e formação de preços: conceitos, modelos e instrumentos: abordagem do capital de giro e da margem da competitividade. (3 ed.). São Paulo: Atlas.

FREUND, F. T. (2005). Alimentos e bebidas: uma visão gerencial. (2 ed.). Rio de Janeiro: Senac Nacional.

GIL, A. C. (2008). Métodos e Técnicas de Pesquisa Social. (3 ed.). São Paulo: Atlas.

KOTLER, P. (1998). Administração de marketing: análise, planejamento, implementação e controle. (5 ed.). São Paulo: Atlas.

LAKATOS, E. M.; MARCONI, M. A. (2010). Técnicas de pesquisa: planejamento e execução de pesquisas, amostragens e técnicas de pesquisa, elaboração, análise e interpretação de dados. (7 ed.). São Paulo: Atlas.

LAS CASAS, A. L. (2006). Marketing: conceitos, exercícios e casos. São Paulo: Atlas.

LEONE, G. S. G. (2009). Curso de contabilidade de custos. (3 ed.). São Paulo: Atlas.

LÔBO, A. (2009). Manual de estrutura e organização do restaurante comercial. (2 ed.). rev. São Paulo: Editora Atheneu.

MACHADO, A. V.; MACHADO, M. R.; HOLANDA, F. M. A. (2006). Análise do Processo de Formação de Preços do Setor Hoteleira da cidade de João Pessoa/PB: Um estudo Exploratório. In: XXX EnANPAD. Anais Eletrônicos XXX EnANPAD. Salvador/BA: ANPAD, 23 a 27 set. 2006.

MARTINS, E. (2008). Contabilidade de custos. (9 ed.). São Paulo: Atlas.

MILAN, G. S.; TONI, D.; LARENTIS, F.; GAVA, A. (2008). Entendendo o processo de formação e definição de estratégias de preço: um estudo exploratório em empresas da Serra Gaúcha. In: XXVIII Encontro Nacional de Engenharia de Produção. 2008. Anais Eletronicos XXVIII ENEGEP. Rio de Janeiro: ENEGEP, 13 a 18 de outubro de 2008.

SEBRAE. (2010). Restaurante Self Service. Rio de Janeiro: SEBRAE. Disponível em: 
<http://www.google.com.br/url?sa=t\&rct=j\&q=classifica\%C3\%A7\%C3\%A30\%20dos\%20 self\%20sevice\%20de\%20acordo\%20com\%200\%20sebrae\&source=web\&cd=2\&ved=0C CIQFjAB\&url=http\%3\%2F\%2F201.2.114.147\%2Fbds\%2FBDS.nsf\%2FCA2CB9703DF2 AB47832578A4006B32C8\%2F\%24Fe\%2FRestaurante\%2520Self\%2520Service.pdf\&ei =cbOqTvT4PILZgQei793WDw\&usg=AFQjCNHnU5y2TL_RCw3L9gJyhP2aBxWaw\&sig2 $=70 k u G K s n E F F 3 A N 6 f i R n t T Q>$. Acesso em 30/abr/2011.

SENAC. (2008). Bares e Restaurantes: gestão de pequenos negócios. Rio de Janeiro: Senac Nacional.

VENTURI, J.; LENZI, F. C. (2004). Administração empreendedora aplicada em restaurantes turísticos na cidade de Ipanema, litoral norte de Santa Cataria. Revista eletrônica de turismo, vol. 3, n. 2.

YIN, R. K. (2005). Estudo de Caso: planejamento e métodos. Tradução de Daniel Grassi. (3 ed.). Porto Alegre: Bookman.

Data de Submissão: 15/03/2013

Data de Aceite: 19/10/2013 